\title{
Experiência social e identidades: trabalhadores migrantes na plantation canavieira
}

\author{
Marilda Aparecida de Menezes*
}

Migrantes SAZONAIS nA PLANTATION CANAVIEIRA

A migração sazonal do Agreste do Estado da Paraíba para a plantation canavieira na Mata Seca do Estado de Pernambuco remonta pelo ao menos até princípios do século XX. Apesar desta longa tradição, tem ocorrido uma intensificação do uso de 'trabalhadores migrantes' localmente chamados corumbas desde a década de 80. A literatura geralmente explica este fenômeno como resultado da diferença entre a quantidade de trabalho requerido durante as fases do ciclo agrícola da cana-de-açúcar. Durante a safra, um número maior de trabalhadores é necessário em comparação com as fases de cultivo e limpa da cana, sendo o número de trabalhadores locais não suficiente para atender esta demanda, se contrata trabalhadores de fora. Apesar desta explicação ser verdadeira, há também evidência de que o recrutamento intensivo de trabalhadores migrantes é o resultado da racionalização e controle político dos trabalhadores.

As transformações das relações de trabalho na plantation canavieira envolvem uma complexa segmentação dos trabalhadores, que segundo Novaes (1993) pode ser compreendida através de quatro critérios principais. Primeiramente, segmentação por gênero, com diferenças entre os trabalhadores masculinos e femininos; segundo, por idade, com diferenças entre trabalho infantil e adulto; terceiro, por formas de controle do trabalho, entre os trabalhadores legais e ilegais, localmente chamados fichados e clandestinos. Finalmente, segmentação pelo local de residência, critério que explica a categoria de 'trabalhadores migrantes', a qual é objeto do presente trabalho. Considerando o lugar de residência, três categorias podem ser identificadas:

- Locais: são os ex-moradores e os trabalhadores assalariados que vivem no município ou na área próxima à usina, retornam para casa ao final da jornada

* Professora da Universidade Federal da Paraíba, Campus de Campina Grande. 
diária de trabalho. Devido à expulsão intensa dos moradores desde a década de 50, os trabalhadores assalariados têm se tornado o grupo majoritário entre os trabalhadores da cana-de-açúcar (Sigaud, 1981, p. 182), podendo ser permanentes ou temporários, legal ou ilegal, homem ou mulher, criança ou adulto.

- Trabalhadores assalariados de fora: são aqueles que vivem na área da plantation canavieira na Região Costeira do Nordeste e que circulam entre as usinas, seja entre municípios do mesmo Estado ou de outros Estados. Eles em geral ficam a semana alojados em galpões e nos finais de semana ou de cada duas semanas retornam para casa (Novaes, 1993, p. 234). Não há uma clara distinção entre estes trabalhadores e os locais, eles se empregam tanto na área de sua moradia ou fora, pertencendo tanto à categoria de 'locais' ou de 'fora'. Entretanto, esta diferenciação tem impactos sobre a organização dos sindicatos cuja estrutura organizacional é delimitada pelo município.

- Camponeses - trabalhadores migrantes: são os tradicionais corumbas. Eles procedem das Regiões do Agreste e Sertão, são trabalhadores sazonais que combinam agricultura de subsistência com trabalho assalariado na plantation canavieira ou outras atividades. Denominamo-los de camponeses - trabalhadores migrantes e não trabalhadores migrantes da plantation canavieira porque eles mantêm vínculo com a terra e também migram para cidades do Sudeste brasileiro, freqüentemente permanecendo longos períodos.

Reconhecemos que é importante considerar a complexidade da segmentação dos trabalhadores canavieiros, como por exemplo as diferenças entre 'locais' e 'de fora', assim como outros grupos como mulheres e crianças. No entanto, este artigo investiga a posição social dos tradicionais corumbas na referida segmentação social dos trabalhadores canavieiros no Estado de Pernambuco. Tomamos como estudo de caso a Usina São José, no município de Igarassu, Estado de Pernambuco. Esta usina pertencia até 1995 ao Grupo Votorantim e foi comprada em 1995 pelo Grupo Petribu.

O aumento da contratação de trabalhadores migrantes e trabalhadores de fora neste contexto político não se explica apenas pelas peculiaridades ecológicas do ciclo da cana-de-açúcar, mas antes como um mecanismo de controle do trabalho para alcançar altos níveis de produtividade e lucratividade (Novaes, 1993, p. 115). Em relação à plantation canavieira no Estado da Paraíba, alguns autores já mostraram que houve um aumento do número de migrantes sazonais durante as décadas de 80 e 90, Moreira (1995, p. 212-3) explica que este fenômeno resulta das ações sindicais assim como das transformações na agricultura da Região Agreste.

Segundo os gerentes da usina, os trabalhadores locais são altamente influenciados pelas ações dos sindicatos, que estimulam a preguiça, indisciplina e baixa produtividade dos trabalhadores. Este discurso se constrói na luta contra a significativa 
atuação dos sindicatos de trabalhadores rurais na área canavieira do Estado de Pernambuco, os quais tem lutado desde o período da redemocratização nos anos 70 por direitos trabalhistas, incluindo o direito de organização e expressão sindical. Em 1979 os sindicatos da área canavieira promoveram a primeira greve de trabalhadores rurais desde o golpe de estado de 1964. De um lado, este movimento representou uma das forças líderes na redemocratização das relações de trabalho na agricultura e apresentou algumas características que o distinguiram das greves urbanas (Sigaud, 1980, p. 9-10). De outro lado, este movimento representou a reemergência da mobilização social entre os trabalhadores rurais do Nordeste do Brasil entre as décadas de 50 e 60 antes da Ditadura Militar (Idem, p. 12).

A estratégia de contratar trabalhadores migrantes como uma resposta ao aumento da organização dos trabalhadores não é utilizada apenas nos Estados do Nordeste Brasileiro (Novaes, 1993), mas é também comum em outros estados e países. Mencionaria aqui três exemplos. Primeiro, o caso da Republica Dominicana na América Central, analisado por Baud (1992); segundo, o caso de migrantes na plantation canavieira na Índia, analisado por Breman (1985); e finalmente, trabalhadores migrantes nos Estados Unidos, analisado por Burawoy (1976). O exemplo dos Estados Unidos é mais complexo que a migração sazonal interna no Brasil, porque envolve questões jurídicas relativas à condição de cidadãos estrangeiros, o que tem sérias conseqüências para os direitos e condições do trabalho.

Para Breman (1985), o funcionamento do mercado de trabalho se explica mais por fatores políticos e de controle do trabalho do que preço do trabalho:

"trabalhadores migrantes são mais baratos, mas isto é uma vantagem acidental e não a razão principal pela qual eles são preferidos (...) O rebaixamento das faixas salariais é muito mais um efeito do que um objetivo do excedente de oferta de trabalho" (Breman, 1985, p. 335).

Para os migrantes que trabalham em fazendas nos Estados Unidos, Burawoy diz:

"Quando o trabalho doméstico ameaça de se organizar, ele é deslocado pelo trabalho migrante - externo ou interno - ou violentamente reprimido" (Burawoy, 1976, p. 1072).

Os fazendeiros tem grande controle sobre os trabalhadores migrantes, porque eles estão continuamente disponíveis para todos os tipos de tarefas, desde a madrugada até bem tarde na noite, são diligentes, conscienciosos, corretos e dóceis (Breman, 1985). Baud expressa o mesmo ponto de vista com referência aos migrantes haitianos que trabalham na República Dominicana. Ele diz que é difícil controlar nativos e em muitas partes do mundo, o trabalho migrante tem sido recrutado de 
regiões distantes mesmo existindo uma reserva local. No caso do Nordeste Brasileiro, Novaes (1993) diz que os trabalhadores migrantes são preferidos pelos gerentes da usina porque eles são mais submissos ao controle da usina do que os locais. Eles são mantidos isolados dentro da propriedade da usina e aceitam novas normas e regras mais facilmente que os locais. Em resumo, podemos dizer que a literatura mencionada enfatiza que os trabalhadores migrantes tendem a ser diligentes, passivos, dóceis e submissos às regras trabalhistas, o que enfraquece o movimento dos trabalhadores (Breman, 1985; Baud, 1992; Moodie, 1991; Novaes, 1994).

\section{CAMPONESES E MIGRANTES: AS MÚLTIPLAS IDENTIDADES}

A noção de que os trabalhadores migrantes são passivos, submissos, produtivos será contrastado com sua experiência social no contexto das relações de trabalho na plantation canavieira no Estado de Pernambuco desde a década de 80. Nos baseamos na noção de classe como experiência social proposta por Thompson:

"Por classe, entendo um fenômeno histórico, que unifica uma série de acontecimentos díspares e aparentemente desconectados, tanto na matéria-prima da experiência como na consciência. Ressalto que é um fenômeno histórico. Não vejo a classe como uma 'estrutura', nem mesmo como uma 'categoria', mas como algo que ocorre efetivamente (e cuja ocorrência pode ser demonstrada) nas relações humanas" (Thompson, 1987, p. 9)

Examinaremos classe como experiência social em três formas principais. Primeiramente, através da noção de 'práticas cotidianas de resistência' conforme proposto por Scott (1985). Este autor revisou a literatura sobre organizações camponesas e concluiu que o comportamento político dos camponeses tem sido analisado de duas perspectivas principais, eles são compreendidos como submissos, passivos e medrosos ou como atores de insurreições camponesas.

"Nós não podemos esquecer o fato de que a ação do campesinato tem se transformado ou tem-se diminuído as opções políticas colocadas ao estado. É neste sentido e não através de revoltas, considerando a pressão política legal, que o campesinato tem classicamente marcado sua presença política. Então, qualquer história ou teoria da política camponesa que busque fazer justiça ao campesinato, como um ator histórico, deve necessariamente considerar o que eu escolhi chamar formas cotidianas de resistência” (Scott, 1985, p. 35).

Scott reafirma que considerar classe como experiência significa observar a comunidade camponesa, parentesco, vizinhança, facção, rituais como espaços de identidade humana e solidariedade. 
“....a realidade desordenada de identidades múltiplas continuará sendo a experiência de onde as relações sociais são conduzidas. Nem camponeses nem proletários derivam suas identidades diretamente ou somente do modo de produção, e quanto mais nós observamos as experiências concretas da classe como elas são praticadas, mais poderemos avaliar os obstáculos e as possibilidades para a formação de classe" (Idem, p. 41).

Como 'práticas cotidianas de resistência' não são tão visíveis como os eventos formais e coletivos, há dificuldades metodológicas em identificá-las assim como compreendê-las num quadro teórico sistemático. Scott sugere que uma forma de lidar com este problema seria a abordagem de estudos detalhados da cultura de um grupo subordinado e sua relação com os valores da elite dominante.

"os valores que os pobres estão defendendo são na maioria, sem exceção, vinculados aos seus interesses materiais como uma classe. Nós estaríamos, entretanto, equivocados quanto à natureza total da luta se nós nos limitássemos apenas aos efeitos materiais" (Scott, 1985, p. 235).

Pensamos que a perspectiva teórica sugerida por Scott permite uma alternativa a outras abordagens que atribuem características de passividade, conformismo, fatalismo, imobilismo aos camponeses ou trabalhadores que não estão envolvidos em revoluções ou mobilizações abertas.

Uma segunda forma de entender classe como experiência é considerá-la como um processo subjetivo ou como alguns autores tem considerado, como vinculada à estratégias de vida. Harries propõe a seguinte definição:

"Proletarização é um processo objetivo, significando uma dependência crescente da venda da força-de-trabalho para a sobrevivência; mas é também um processo subjetivo, uma experiência que é construída pelas pessoas de uma forma específica a qual é expressa em formas diversas e concretas. Consciência de classe não foi apenas estruturalmente determinada pela economia política, mas foi também herdada, construída e adaptada pelos indivíduos que desejam dar um significado e ordem às suas vidas" (Harries, 1994, p. 223).

Harries propõe a concepção esboçada acima para compreender as múltiplas identidades de camponeses-migrantes que trabalharam em campos de cana-de-açúcar e minas de ouro na África do Sul no começo do século vinte. As identidades dos trabalhadores migrantes estudados são múltiplas, formadas por sua condição como camponeses, canavieiros, trabalhadores urbanos e por outras estratégias de sobrevivência. Estas múltiplas identidades requerem uma abordagem de consciência de classe que ultrapasse as fronteiras de uma categoria específica de trabalhadores e tente entender como a múltipla condição social interfere no comportamento 
político dos migrantes. Neste sentido, consideramos que a noção de consciência de classe proposta por Harries é apropriada para entender as identidades dos migrantes. Ele conclui que as práticas cotidianas de resistência expressam as alternativas utilizadas pelos migrantes mais para proteger a sua cultura não-capitalista do que como forma de expressar sua oposição à classe capitalista. Como conseqüência, não há solidariedade de classe mas laços culturais como uma rede de significação (Harries, 1994, p. 222-27). Argumentaremos que os migrantes, mesmo articulados às redes sociais do lugar de origem e à sua condição camponesa, têm também se definido como trabalhadores canavieiros em oposição aos usineiros e gerentes.

A concepção de consciência de classe como um processo subjetivo é também proposto por Bozzoli (1991) que estudou os processos de consciência de um grupo de mulheres idosas que migraram ao longo de suas vidas e retornaram à sua comunidade de origem. Ela afirma:

"Um argumento básico deste livro é que a consciência destas mulheres em Phokeng é organizada em torno do que eu tenho chamado estratégia de vida (...) Isto sugere que consciência é formada historicamente, dentro de um nexo de estruturas (sim, estruturas), experiências, relacionamentos, e eventos, e que não pode ser entendida utilizando-se um método puramente estrutural ou sincrônico de análise" (Bozzoli, 1991, p. 236-39).

Consideramos que a proposição de Bozzoli é suficientemente ampla para incorporar os diferentes aspectos que modelam a consciência de classe e não priorizar apenas um aspecto tal como a estrutura ou a estória individual. Durante o desenvolvimento da análise, mostraremos como a consciência dos migrantes não apenas se demarca por suas estratégias de vida mas também por suas experiências enquanto canavieiros. Suas identidades assumem diferentes formas em diferentes situações e podem também variar ao longo de suas vidas.

A terceira expressão de classe como experiência social são os movimentos coletivos ou organizações formais conduzidas pelos sindicatos. Apesar da concepção de que os trabalhadores migrantes tendem a enfraquecer o movimento dos trabalhadores, a sua experiência social tem revelado que eles também têm aderido a movimentos coletivos e incorporado uma orientação sindicalista. Iremos analisar as práticas cotidianas de resistência para mostrar como as identidades dos trabalhadores migrantes têm se transformado como resultado das interações sociais com outros grupos de canavieiros bem como da ação dos sindicatos.

Alguns autores que tem estudado diferentes grupos de migrantes propõem entender identidades como abertas, circunstanciais e múltiplas.

Harries (1994) afirma: 
"Eu adoto a visão de que identidade é situacional e fluida mais do que um produto orgânico de uma comunidade delimitada" (Harries, 1994, p. XIX)

Rutherford diz:

"Identidade nunca ocupa um lugar estático, ela contem traços do seu passado e do que tornar-se-á" (Rutherford, 1990, p. 22)

Temple argumenta que identidade é negociada e está em mutação:

“...as definições do que se considera "Polones" ou "Porto- riquenho" não eram nem fixas nem indisputáveis, ao contrário, elas eram negociadas e em transformação" (Temple, 1994b, p. 11)

Benmayor and Skotnes diz:

"Identidade é construída, multi-facetada, negociada, situacional ou de acordo com muitos fragmentada" (Benmayor e Skotnes, 1994, p. 9)

Resumindo as idéias apresentadas pelos autores citados abaixo entendemos que identidades são abertas, circunstanciais e situacionais, fluidas, em transformação, multi-facetadas e negociadas.

A experiência social dos migrantes revela que eles mesmos assim como os trabalhadores locais percebem mudanças em suas identidades, demonstrando o caráter fluído e situacional e não como demarcadores sociais fixos, estáticos ou definidos por algumas idéias pré-concebidas.

Alguns autores que têm estudado classe e consciência na perspectiva que adotamos aqui têm recorrido a metodologia de pesquisa baseadas em história oral ou trabalho etnográfico. Por exemplo, Bozzoli (1991) baseou seu estudo principalmente em histórias de vida. Outros têm recorrido a história oral e etnografia, este é o caso do estudo de Boeschoten sobre camponeses na Grécia.

"Há duas razões pelas quais eu adotei esta abordagem metodológica. Primeira, porque as entrevistas de história oral oferecem uma narrativa de primeira mão sobre as visões dos camponeses. Em outras palavras, elas revelam que o 'transcrito invisível' como proposto por Scott (1985, p. 32) não necessariamente significa a 'estória verdadeira' mas a interpretação dos camponeses. Segundo, o estudo de comunidade em pequena escala nos coloca em posição estratégica para acompanhar as expressões da consciência camponesa: uma análise detalhada de comunidade nos possibilita conectar percepções dos camponeses no contexto da economia e estrutura social da comunidade, assim como do desenvolvimento da nação" (Boeschoten, 1993, p. 615-6)

Este artigo se baseia tanto em fontes de história oral quanto em trabalho etnográfico. 


\section{PrÁtICAS dE RESISTÊNCIA E ESTRATÉGIA DE VIDA}

As relações de trabalho são anualmente negociadas entre os sindicatos, associações de usineiros e o Estado e os acordos firmados são consolidados na Convenção Coletiva. Apesar deste documento ter um status legal e deveria ser cumprido pelos usineiros, ele é regularmente desrespeitado, negando aos trabalhadores alguns direitos básicos garantidos em lei. Um dos aspectos da Convenção Coletiva é a regulamentação da Tabela de Tarefas, que estabelece os preços para quantidades definidas de produção para as diversas atividades, tais como limpa, plantio e corte da cana. Apesar deste regulamento, os supervisores da usina se utilizam de diversas estratégias para subestimar a produção diária dos trabalhadores. Os migrantes que na sua maioria trabalham como cortadores de cana entendem que a pesagem da cana é um roubo. Eles são conscientes que produzem mais do que é registrado pelos inspetores, vários eventos são contados nas entrevistas que evidenciam não apenas uma percepção clara dos trabalhadores de que estão sendo roubados como também a evidência empírica do fato. Isto, no entanto, não tem desencadeado necessariamente ações de enfrentamento e contestação junto aos gerentes da usina.

De modo geral, os trabalhadores migrantes enfrentam o 'roubo' de quatro principais formas. Primeiro, aceitando as condições impostas sobre eles. Segundo, através de confrontos pessoais com os supervisores da usina no momento da pesagem da cana. Aqueles que reagem estão sujeitos a sanções, tais como ser removido para atividades mais pesadas e pior pagas, ser suspenso por três dias sem pagamento ou ser demitido. Terceiro, chamando o representante do sindicato e pedir para o cabo e/ou fiscal da usina repesar a cana. Esta atitude é também fortemente controlada pelos gerentes da usina. Finalmente, deixando a usina e indo à outra, retornando para casa ou migrando para lugares distantes como Rio de Janeiro, São Paulo, Brasília.

O controle repressivo sobre os trabalhadores faz com que o confronto pessoal ou a participação do sindicato no peso da cana sejam mais raros e isolados. A atitude mais comum tem sido aceitação do 'roubo' ou de outras condições de controle do trabalho ou romper o contrato de trabalho. 'Aceitação' poderia ser considerada uma expressão de conformidade, passividade e submissão dos trabalhadores migrantes. Entretanto, propomos aqui entender esta atitude de duas perspectivas. Primeiro, situar 'aceitação' dentro do conjunto de alternativas que cada indivíduo tem recorrido ao longo de sua vida. Segundo, entender 'aceitação' em relação à múltipla condição social dos migrantes, os quais são simultaneamente camponeses e trabalhadores urbanos em diversos lugares do Brasil. Histórias de vida e entrevistas semi-estruturadas são uma fonte rica de informações sobre como os migrantes combinam as alternativas disponíveis a eles com seus interesses individuais, 
circunstâncias especiais num dado momento de suas vidas e suas identidades. Neste sentido, uma pessoa pode 'aceitar' o roubo na pesagem da cana por muitos anos mas num determinado momento tomar atitudes que ameacem seu emprego, como por exemplo, chamar o representante do sindicato para reivindicar o peso correto da cana, ter uma confrontação pessoal com os supervisores da usina, se envolver em algumas ações coletivas promovidas pelos sindicatos, tais como as greves ou demonstrações públicas ou ainda abrir questão jurídica contra a usina. Através da análise das histórias de vida é possível verificar que os indivíduos têm diferentes atitudes ao longo de suas vidas. Apresentarei fragmentos de três histórias de vida de migrantes, que ilustrarão esta afirmação. O primeiro caso é Edvaldo, que após ter trabalhado alguns anos na Usina São José decidiu reivindicar seus direitos trabalhistas através da justiça. Ele diz:

"eu num fiz nem confusão com o administrador, nem com os fiscais e nem com o cabo. Então eu aconselhava: olha gente, é o seguinte, vamos esperá com paciência, vamos terminá e ir embora porque o tumulto e a confusão num, num resolve nada, nada.? Se tivesse o meu pensamento, eu digo: vamos sair daqui quetinho, tudo bem; agora, aquele que tiver... coragem, então que é disponível, então é correr atrás do seu suor derramado na luta. Este é o problema que eu vou procurar aqui...(Edvaldo, fita 25:2)

O segundo caso é de Geraldo, que nunca abriu questão jurídica, mas decidiu sair da usina e ir para o Rio de Janeiro.

"Apesar de tudo eles tiram muito na cana que a gente faz. A gente sente um pouquinho, que eles tiram. Não, mas a comida não vai ser cobrada, mas a gente paga, na cana. A gente faz tanto, mas só ganha tanto na cana, na medição da cana. Porque ali eles tiram o preço do comer que eles dão a gente. Porque a gente sente, o trabalhador sente, quanto é que ele faz por dia. Mas mesmo assim, com relação à Paraíba, tá trabalhando aqui um dia dos fazendeiro é melhor, não é? A gente tem um direitinho pouco, quando sai, quando mandam embora, quando mandam a turma toda embora, o direito é pouco, né ?? (Geraldo, fita 1993: 4)

O terceiro caso é Orlando, cuja narrativa mostra diferentes formas de lidar com a exploração do trabalho na usina. Selecionamos alguns trechos de sua narrativa que ilustra este ponto. A conexão entre os trechos é construída pelo nosso próprio entendimento e conseqüentemente não deriva de sua narrativa.

"Eu já trabalhei muito pelo mundo e sei como é que é. No Rio de Janeiro se ganha quanto, 60 conto por semana, 70, mas esta hora ninguém nem sonha largar, larga de 10 horas da noite. Em Pernambuco se ganha 45, 50, ate 70 e até 
mais, mas não trabalha de noite. $\mathrm{O}$ ano passado o máximo que eu cheguei a ganhar por semana foi até 63, porque foi muito difícil. Porque quando uma pessoa pega uma usina, como foi que o homem pegou (se refere ao novo dono), a gente tem que alcançar todo tipo de entendimento. Mas tem muita gente que não entende, acha que foi ruim demais (Orlando, fita 53: 5)

Nesta parte de sua narrativa Orlando enfatiza que os salários nas usinas de cana-de-açúcar não são ruins se comparado com os salários no Rio de Janeiro. Em outras partes, ele explica que para uma pessoa casada é mais vantajoso trabalhar nas usinas, pois está próximo de sua casa. Esta avaliação é recorrente para outros migrantes, para os quais as possibilidades de trabalhar distante de sua área de origem não parecem atraentes em comparação com o trabalho na cana-de-açúcar. Os migrantes também comparam as condições de trabalho nas usinas que recrutam trabalhadores de suas regiões. As diferenças entre as percepções individuais sobre as alternativas de sobrevivência afetam não apenas os padrões de migração e mobilidade do trabalho, mas também se incorporam nas formas como se avaliam as relações de trabalho na cana-de-açúcar.

Em outras partes da narrativa de Orlando, ele reafirma sua posição de 'aceitação’ das regras de controle do trabalho e de não tomar nenhuma ação contra a usina.

"Porque a senhora sabe que realmente quanto mais nós sai de firma e bota ela em questão, mais perdido a gente fica, porque olha, uma usina como aquela São José, que nem a Matari, que nem a Santa Tereza e a Maravilha. Aí a gente aqui de Fagundes, 100, 200 homens vamos botar no pau, vamos, bota no pau, o ano que vem não ficha lá. Vai prá outra. Tem o outro ano, tem os 3 anos e aí nos 3 anos, fechou o beco e aí vai trabalhar onde, aqui já tem muito que trabalha na Usina São José, ganhava pouquinho mas ganhava, hoje tá abandonado lá pro Rio de Janeiro, tem muitos querendo vim se embora e não pode, porque, as vezes não arrumou emprego" (Orlando, fita 53: 7)

Surpreendentemente, no final da entrevista, quando ele fala de seus planos para o futuro, ele expressa sua intenção de levar a usina à Justiça. É importante registrar que a entrevista foi conduzida informalmente, dando oportunidade para o migrante contar sua história em seu próprio modo. No caso de Orlando, apenas interferimos para esclarecer algumas idéias que se referiam a pontos anteriormente mencionados. A narrativa sobre seus planos futuros na usina apareceu logo após ter contado sobre a greve de Dezembro de 1995 e o convite que havia recebido para se tornar um delegado sindical, o que ele não aceitou.

"Eu conversando mais aquele pessoal do sindicato, eles queriam botar eu prá ser delegado do sindicato de Igarassu, mas mode eu ficar tomando conta de 
Água Branca, o que acontece comigo. Adepois pega um cara daqueles ali, dá um tostão a ele qualquer e manda dá um tiro em mim e eu fico morto, que só o que encontra ali é caveira de gente, né e eu vou perder a minha vida prá ganhar a minha mixaria de dar de comer aos meus filhos, não precisa disto. Quando não der certo prá mim trabalhar num lugar mais, eu mudo de patrão e deixo lá tudo em paz. Agora este ano eu vou ver as circunstâncias como é que vai, porque prá mim deixar a usina, eu tenho que deixar de uma vez e não ir mais atrás dela, eu tenho 4, com esta safra faz 5, eu vou conversar lá com o advogado e saber quanto será que vai dar prá mim receber destes tempos, se der uma coisa que compense, prá me dar uma ajudinha, eu vou e entro em acordo com ele, eu vou e boto na questão, e recebo lá na usina e lá não volto mais (Orlando, fita 53: 8).

Analisando a narrativa de Orlando, é notável que sua intenção de abrir questão contra a usina segue a parte onde ele diz que prefiriria deixá-la e ir para outro emprego caso avaliasse que o trabalho na usina não fosse mais adequado à ele. Em outros termos, as quatro alternativas utilizadas pelo conjunto dos camponesesmigrantes se expressa na forma em que um único trabalhador entende as relações de trabalho. A narrativa de Orlando ilustra como as quatro formas mencionadas previamente em relação as formas de lidar com as regras da usina podem ser encontradas numa história de vida de um único trabalhador.

As citações acima sugerem três pontos em relação à estratégia de 'aceitação' das regras da usina. Primeiro, esta atitude pode ser interpretada como a única alternativa possível num contexto repressivo. Ela é a única que traz menores riscos para os trabalhadores em termos de manutenção de seus empregos e é uma estratégia de proteção contra as medidas repressoras tomadas pelos gerentes da usina. Segundo, analisando-se as histórias de vida, é possível identificar diferentes atitudes ao longo de uma vida singular, isto questiona algumas polarizações tais como entre as noções de passividade, submissão contra confrontação, reação legal e movimentos coletivos. Terceiro, é possível identificar um relacionamento entre ação e interesse individual. A intenção ou decisão de abrir questão legal contra a usina geralmente acontece quando os migrantes querem ou contam com a possibilidade de desligamento da usina. Isto significa que uma ação legal contra a usina, a qual se inscreve nas práticas políticas sindicais, também se conecta com interesses individuais. As atitudes que se diferem da 'aceitação' tais como deixar a usina ou levá-la à justiça emergem quando o migrante não está preocupado em perder o emprego e tem outras alternativas em vista. Estas incluem se empregar em outras usinas, migrar para lugares distantes como cidades na Região Sudeste do Brasil ou retornar para área de origem. Em outras palavras, o auto-interesse derivado de circunstâncias individuais e familiares desempenha um papel essencial nas práticas cotidianas de resistência, como Scott (1986, p. 26) afirmou: 
"Ignorar o auto-interesse na resistência camponesa é ignorar o contexto determinado, não apenas de política camponesa, mas da política da maioria das classes pobres. É precisamente a fusão entre o auto-interesse e resistência que constitui a força vital que anima a resistência dos camponeses e proletários".

A decisão de deixar a usina, seja formalmente através da interrupção do contrato de trabalho, ou informalmente através do 'abandono' do trabalho em geral se articula com possibilidades de trabalhar em outras usinas, em áreas urbanas distantes, ou de retornar para casa. Estas alternativas se tornam disponíveis através de redes sociais que são formadas por parentesco ou relações de amizade. Redes sociais constituem um recurso cultural fundamental para os migrantes, não apenas para compartilhar informações sobre empregos, mas também como espaço social para compartilhar experiências de trabalho. Este aspecto também foi observado entre os migrantes em minas de ouro e plantation canavieira na África do Sul.

"A facilidade em que os trabalhadores se conectam a amigos e parentes e desertam em grupos sugere a existência de uma rede de informações e organização que é tanto informal quanto invisível" (Harries, 1994, p. 55)

As narrativas orais são uma rica fonte de registro e explicação de práticas de resistência. Um migrante da Usina São José diz:

"Eu sou da Paraíba, mas eu não me submeto, eu conheço Rio de Janeiro, Brasília, apenas falta São Paulo...” (RAP, 1.12.95: 1).

Outro da Usina Central Olho D’ Água relatou que se a usina não melhorasse, ele iria ao Rio de Janeiro (RSPM, Outubro 1994). Claúdio que trabalhou por 40 anos em plantation canavieira relata:

"Em qualquer companhia que trabalho, se o homem (gerente) não vê que o trabalho feito merece ser bem pago, eu peço para ser mandado embora e deixo" (Cláudio, fita 22: 16).

Apesar de que a decisão de deixar o emprego é realizada numa base individual, há alguma evidência que esta tem sido uma estratégia praticada por um número significativo de trabalhadores. Isto pode ser oficial, quando os trabalhadores pedem demissão ou não oficial, quando eles simplesmente param de vir trabalhar. Neste último caso, a carteira profissional fica 'suja', caracterizando um 'mal trabalhador', o que afetará negativamente o processo de seleção no próximo emprego. Para evitar tal estigma, os trabalhadores tendem a tirar outra carteira profissional alegando que perderam a anterior. A existência de uma ou mais carteiras de trabalho é uma das estratégias de driblar o rigoroso processo de seleção dos trabalhadores seja nas usinas ou em outros empregos. De acordo com informações fornecidas 
pelos arregimentadores que recrutam migrantes de Fagundes para a Usina São José durante a safra 1994/95 existia a seguinte situação:

- 66 candidatos: 43 selecionados, 23 não selecionados pelos seguintes motivos:

- 4 não passaram no exame médico;

- 2 tinham ação trabalhista contra a usina;

- 17 tinham abandonado ou interrompido o contrato de safra em anos anteriores;

Dos 43 trabalhadores-migrantes selecionados, 7 deixaram a usina e foram ao Rio de Janeiro. $\mathrm{Na}$ Usina Matary, 12 migrantes deixaram o emprego ao mesmo tempo e de 100 trabalhadores recrutados no começo da safra de 1994/5, apenas 16 trabalharam até o final da safra. Detalhes da imagem negativa desta usina se espalharam rapidamente entre os trabalhadores em seus lugares de origem, sendo que o arregimentador encontrou enorme dificuldade em encontrar os 50 trabalhadores requeridos pela usina. Na safra 1995/6, de acordo com informações fornecidas pelo arregimentador de Fagundes para a Usina São José, havia 123 trabalhadores contratados, dos quais 17 interromperam o contrato antes da finalização da safra.

Os trabalhadores desistem do emprego seja individualmente ou em pequenos grupos, geralmente formados por parentesco e redes de amizade. Dois irmãos e três amigos que estavam trabalhando na Usina Matary na safra 1994/95 solicitaram demissão e foram trabalhar ilegalmente em outra usina. Apesar dos números citados referirem-se apenas a poucos grupos de migrantes e apenas a duas safras, eles proporcionam evidência de como 'deixar o emprego' tem se tornado uma prática persistente de resistência. Apesar de que é uma decisão individual, ela tem sido comum entre os trabalhadores e tem afetado as técnicas de controle do trabalho. Um dos gerentes da Usina Santa Teresa, que é localizada no município de Goiana, argumentou:

'Três ou quatro anos atrás a safra estava sob risco por causa do número de trabalhadores que tinham abandonado o trabalho. Hoje, a usina tem um sistema melhor de controle na seleção dos trabalhadores e isto tem sido um elemento de ameaça e controle sobre o 'abandono de trabalho' ou a decisão de interromper o contrato de safra'.

Como é argumentado pelo gerente na citação acima, um dos critérios de seleção dos trabalhadores tem sido o cumprimento do Contrato de Safra em usinas anteriores. Apesar da maior racionalização dos mecanismos de controle dos trabalhadores, há evidência de que a interrupção do Contrato de Safra, seja oficialmente ou simples 'abandono' de trabalho, tem se constituído num fato recorrente. Isto revela que, apesar de algumas práticas cotidianas de resistência serem conduzidas a nível individual, elas podem se expressar de forma persistente e recorrente entre um número expressivo de trabalhadores e assim influenciar as relações de trabalho. 
Como Scott explica, práticas cotidianas de resistência se referem a um 'padrão consistente':

"Quando tais atos são raros e isolados, eles são de pouco interesse, mas quando eles se tornam um padrão consistente (apesar de que não coordenado e não orientado), estamos lidando com resistência" (Scott, 1986: 26).

Alguns autores têm criticado a idéia de 'práticas cotidianas de resistência' proposta por Scott $(1985,1986)$, por omitir a dimensão político-ideológica (Brass, 1990 , p. 173). Caldeira (1989, p. 27) argumenta que as práticas cotidianas de resistência se referem mais aos mecanismos dos proprietários de controlar a vida local do que as formas que os camponeses agem contra a dominação. Apesar de que o ato de interromper o Contrato de Safra não se constituir uma confrontação com os usineiros ou uma atitude de orientação sindical, quando ele adquire grandes proporções, pode afetar as regras de controle do trabalho. Quando isto ocorre, as fronteiras entre práticas cotidianas e movimentos coletivos e organizados tais como as greves não são facilmente identificadas.

A perspectiva de considerar a saída da usina, oficialmente ou não, como uma prática de resistência é uma proposição construída não apenas de minha própria pesquisa mas também inspirada pela literatura sobre o tema. Van Onselen (1973), estudando os mineiros negros da Rodésia do Sul de 1900 a 1920 afirmou que:

"desertar foi num primeiro momento uma reação africana contra o sistema de trabalho forçado" (Van Onselen, 1973, p. 245)

Harries (1994), que estudou os trabalhadores migrantes em Moçambique e África do Sul no período de 1860 a 1910, também afirma que a mobilidade dos trabalhadores tem se revelado como uma importante forma de resistência. Em que pese as diferenças dos contextos histórico e social do caso estudado, o trabalho forçado em minas da África do Sul é mencionado aqui para mostrar a importância de observar formas invisíveis de resistência, como colocado por Scott (1985).

Apesar de que a 'aceitação' das condições de trabalho e a 'saída' do trabalho aparecem como um traço marcante da identidade dos migrantes, a orientação sindical também emerge como uma referência central. A importância da ação e orientação sindical aparece em vários eventos descritos pelos trabalhadores migrantes.

"Tem uns que aceita, outros num aceita, aqueles que num aceita, aí o cabo falou, o administrador, se num quisé trabalhá pode ir pro barraco... fica lá a vontade, ou vai embora prá casa, que o serviço que tem é esse... aí como o paraibano sai prá trabalhá, né... aí enfrenta tudo o que vim tá pegano, e aquele que num qué trabalhá, aí diz: eu vô atrás do sindicato. Aí vai, aí quando o sindi- 
cato chega, o sindicato fala a verdade, diz que num é daquele jeito. Naquele dia ele obedece, mas no outro dia... ele num vai obedecê mais não (Sílvio, fita 38: 18).

Apesar da consciência do papel do sindicato em solucionar os conflitos entre os trabalhadores e a usina, os migrantes identificam duas barreiras principais em seguir a orientação sindical. Primeiro, eles temem as sanções impostas pela usina sobre os trabalhadores que reivindicam direitos via sindicatos.

"É miserável, no meio assim de 200 pessoas, ele ficam catando assim com a vista, olhando... quem é que tá falando dele, quem é que num tá, se o cara vai consegui, atrás do sindicato, procurá os direito, quando procura seus direito ele manda ir embora... Ele num manda na presença do sindicato, mais no outro dia, ele expulsa a pessoa, e adepois que manda embora, tá mandado, quem tem força é o gerente? (Sílvio, fita 38: 5).

Três trabalhadores migrantes chamaram o sindicato para checar o peso da cana em Dezembro de 1995 e foram removidos para atividades mais difíceis e com menor remuneração (RAP, 8.12.95: 1)

Segundo, os migrantes argumentam que sua condição como 'de fora' e trabalhadores temporários se constitui como uma dificuldade para participar de atividades promovidas pelos sindicatos.

"Nós num participava não, que nós era de fora. Aí nós num participemos não, num participava não. Depois que eles começou combinar com nós, conversar com nós e explicar e nós, o sindicato sempre orientando a nós. (Fernando, fita 9: 25)

"Os pernambucanos são perigoso. O pernambucano arruma muita zoada, arruma, eles têm que medir a cana deles bem medida porque os pernambucanos ali ele não se importa de perder em tudo e não perder e porque tem uma coisa, eles são velhos de firma. Aí tem muitos com vinte anos, trinta anos de carteira assinada, ali o patrão não manda eles ir embora mesmo, né. Se ele vai trabalhar e passa um dia sem trabalhar, o patrão tem que pagar aquele dia à ele, e a gente não. A gente somos novos, nós se assujeita o que eles querem" (Ivo, fita 4:12).

Apesar de que os migrantes constroem um discurso para explicar suas dificuldades em seguirem a orientação do sindicato, eles valorizam a forma como os trabalhadores locais, chamados Pernambucanos, se relacionam com os gerentes da usina no relacionamento cotidiano.

“Os pernambucano são sabido. É por isso que eles (gerentes da usina) não gostam dos pernambucano, que os pernambucano faz greve. Pernambucano faz greve e pernambucano termina logo cedo, e a gente não, ficamo até tarde, pra trabalhar. Por isso que eles não gosta de trabalhar com pernambucano lá. 
Pernambucano são sabido. Eles tem raiva dele lá, porque eles sabe do limite lá. Mas... é por isso que eles não querem os pernambucano, porque qualquer coisinha, vai pro sindicato, o sindicato vem e... mede, pesa a cana deles lá e só trabalha naquele limite. Por isso que eles não querem, chega o povo daqui, chega lá, joga o povo de todo jeito lá, o caba trabalha e ganha pela metade. É... é um castigo mesmo, o cabra vai porque o cara vai ficar aqui parado? Aí vai trabalhar lá, mas... é prá trabalhar prá morrer, prá ganhar micharia. (Cláudio, fita 22: 12)

O reconhecimento de que os Pernambucanos são inteligentes representa a aprovação e admiração dos migrantes em relação aos Pernambucanos, os quais são identificados como possuindo uma consciência sindical. Este entendimento também sugere que certas noções de direitos difundidas pelos sindicatos ou pelos trabalhadores canavieiros locais se incorporam na consciência dos migrantes. A orientação sindical aparece recorrentemente quando os migrantes comparam as usinas. O papel do sindicato na Usina São José é considerado uma das razões principais para explicar melhores condições de trabalho na usina em comparação com outras. Um grupo de trabalhadores - migrantes de Fagundes, que regularmente trabalhavam na Usina São José e que foram na safra 1995/6 trabalhar na Usina Maravilhas no município de Goiana explicou que as condições de trabalho eram piores do que as da Usina São José. Muitos deles deixaram a Usina Maravilha antes do término da safra. Alguns interromperam o Contrato de Safra depois de um mês de trabalho, outros deixaram a usina sem notificação, o que foi caracterizado como 'abandono de trabalho'. Um migrante diz:

"Eu não entendo de jeito nenhum como este pessoal de Itatuba e Ingá aguentam aquilo. Algumas pessoas já trabalhou dezessete safras e sempre com esta exploração. Eu sempre disse aos meus colegas que este era o pior lugar que eu trabalhei e falei sobre a Usina São José, mas o pessoal parecia estar cativo, eles não conheciam outros lugares" (Guilherme, 50 anos).

A citação demonstra que a orientação sindical se incorpora nas formas como os migrantes avaliam e agem em relação ao controle do trabalho. As suas respostas são também moldadas por suas múltiplas identidades enquanto camponeses e trabalhadores migrantes, adesão à uma ou outra alternativa é geralmente conectada com as circunstâncias das relações de trabalho dos canavieiros, sua múltipla condição como camponeses, trabalhadores canavieiros e trabalhadores urbanos e também suas histórias de vida. Vínculos com o lugar de origem e possibilidades de trabalho em outros lugares podem ser justificativas para 'aceitação' das regras e controle do trabalho ou 'saída' do emprego. A análise das intenções, significados envolvidos na forma como uma ou outra alternativa é praticada, ou a diversidade de atitudes que os migrantes podem ter ao longo de suas vidas, tem provado que 
há diferentes percepções e práticas dentro do mesmo grupo de migrantes assim como variações dentro de uma vida. Isto contribui para evitar qualquer polarização entre noções de passividade ou confrontação.

Consideramos difícil estabelecer fronteiras e categorizar rigidamente os demarcadores de identidades e talvez isto não seja possível. Considerando a identidade individual ou grupal, é difícil dizer que as identidades dos migrantes são marcadas por serem trabalhadores canavieiros, camponeses ou trabalhadores urbanos, as múltiplas experiências sociais são incorporadas em suas formas de entender e agir em cada uma destas condições sociais. As práticas sociais e interpretações dos migrantes mostram diversas facetas de suas identidades. Em algumas circunstâncias ou eventos, eles parecem atuar e se perceber como 'trabalhadores locais', assumindo então uma identidade de canavieiro. Em outras ocasiões, eventos ou momentos seus vínculos com a comunidade de origem parecem ser mais dominantes. Encaminhar uma reclamação trabalhista pode simbolizar uma consciência sindical autêntica, mas pode também ser uma estratégia de ganhar dinheiro para comprar terra ou montar um pequeno negócio e se estabelecer na área de origem e assim não mais trabalhar na plantation canavieira. O ativismo dos sindicatos pode estimular a participação do migrante em formas coletivas de resistência, mas a suas ações também podem se orientar mais por práticas cotidianas de resistência. Estas várias possibilidades fazem com que a consciência social seja muito mais complicada que qualquer classificação como passivos, submissos, inconsciente ou sem consciência sindical. As múltiplas identidades como canavieiros, camponeses, trabalhador urbano, proprietários de pequenos negócios são as bases sobre as quais os camponeses - trabalhadores migrantes constroem sua consciência social.

Os pontos levantados acima referentes a identidades múltiplas foram elaborados a partir dos resultados do nosso estudo de caso. No entanto, penso que eles podem ser aplicados a outros tipos de trabalhadores migrantes, como por exemplo, aqueles empregados em construção civil, setores de extração mineral e também trabalhadores engajados nos chamados 'setores informais'. Em outras palavras, conceber identidades como aberta, circunstancial, multi - facetada pode ser uma ferramenta analítica para entender trabalhadores que estão nos degraus mais baixos da estrutura de classe e por não terem uma formação profissional, são levados a procurar trabalho em setores econômicos diversos e também em diferentes lugares, o que resulta em um pertencimento a várias categorias. Esta forma de entender identidade abre perspectivas para abordar consciência social de trabalhadores cuja expressão política não é facilmente identificada e enquanto tal são compreendidos como 'aqueles que faltam consciência'. Eu procurei neste trabalho visualizar os 'transcritos invisíveis' de trabalhadores migrantes de modo a entender a sua consciência social à luz das múltiplas estratégias de sobrevivência assim como sua trajetória de 
vida. Tentamos demonstrar a necessidade de considerar a diversidade de expressões dos trabalhadores em relação ao controle do trabalho dentro de um grupo, como elas se conectam com sua múltipla condição social e como elas variam ao longo de uma vida individual.

\section{BIBLIOGRAFIA}

ANDRADE, S.M.C. Ação Sindical no campo a partir da década de 70: o caso dos trabalhadores canavieiros o. Ph.D. Thesis. São Paulo: Universidade de São Paulo, 1994.

BAUD, M. 'Sugar and Unfree Labour: Reflections on Labour control in the Dominican Republic, 1870-1935'. Journal of Peasant Studies, Vol. 19, No.2, 1992. p. 301-42.

BENMAYOR, R. and Skotnes, A. 'Some reflections on migration and identity'. In: Benmayor, R. and Skotnes, A. (Eds.) Migration and Identity. International yearbook of oral history and life stories, Vol. III, p. 1-18. Oxford: Oxford University Press, 1994.

BOESCHOTEN, R.V. 'The Peasant and the Party: Peasant Options and 'Folk' Communism in a Greek Village'. The Journal of Peasant Studies, Vol. 20, No.4, July 1993, p. 612-639.

BOZZOLI, B. 'History, experience and culture'. In: Bozzoli, B. (Ed.) Town and countryside in the Transvaal: Capitalist Penetration and Popular Response, p.1-47. Cape Town: Ravan Press Ltd, 1983.

BOZZOLI, B. Women of Phokeng. Consciousness, life strategy and migrancy in South Africa, 1900-1983. Portsmouth: Heinemann, London: James Curray, 1991.

BRASS, T. 'Moral economists, subalterns, new social movements, and the (Re-emergence of a (Post-) Modernised (Middle) Peasant'. The Journal of Peasant Studies, Vol. 18, No.1, October 1990, p. 173-205.

BREMAN, J. Of peasants, migrants and paupers: rural labour circulation and capitalist production in West India. Delhi: Oxford University Press, 1985.

BREMAN, J. Wage hunters and gatherers; search for work in the urban and rural economy of South Gujarat. Delhi: Oxford University Press, 1994.

BURAWOY, M. 'The functions and reproduction of Migrant Labor: Comparative material from Southern Africa and the United States'. American Journal of Sociology, Vol. 81, No.5, March 1976, p. 1050-86.

CALDEIRA, T.P.R. A Política dos Outros. O cotidiano dos moradores da periferia e o que pensam do poder e dos poderosos. São Paulo: Brasiliense, 1984.

. 'Antropologia e poder: uma resenha de etnografias americanas recentes'. BIB- Boletim Informativo e Bibliográfico de Ciências Sociais, No. 27, 1989, p. 3-50. 
HARRIES, P. Work, culture and identity: migrant laborers in Mozambique and South Africa, c. 1860-1910. Portsmouth: Heinemmann, Johannesburg: Witwatersrand University Press, 1994.

MENEZES, M.A. Peasant-migrant workers: social networks and practices of resistance. Ph.D. Thesis. Manchester, University of Manchester, 1997. (Org.). Histórias de Migrantes. São Paulo: Edições Loyola, 1992.

MOODIE, D. 'Mine culture and Miners' Identity on the South African gold mines'. In: Bozzoli, B. (Ed.) Town and countryside in the Transvaal: capitalist penetration andpopular response, p. 176-197. Johannesburg: Ravan Press, 1983.

MOODIE, D. 'Social existence and the practice of personal integrity. Narratives of resistance on the South African Gold mines'. African Studies, Vol. 50, No.1-2, 1991. p. 39-63.

MOREIRA, E.R.F. (Coord.) Os caras pintadas de suor e de fuligem da cana [um estudo das condições de vida, saúde e trabalho dos trabalhadores mirins da cana]. Relatório Técnico Final de Pesquisa. João Pessoa: Universidade Federal da Paraíba, 1995.

MORONEY, S. 'The development of the compound as a mechanism of worker control 19001912'. South African Labour Bulletin, Vol. 4 , No.3, 1978, p. 29-49.

NOVAES, J.R.P. Modernização e Relação de Poder: transformações na agroindústria canavieira no Nordeste do Brasil. Ph.D. Thesis. Proograma em Economica da Universidade Estadual de Campinas, 1993.

RUTHERFORD, J. 'A Place called home: Identity and the cultural politics of difference'. In: Rutherford, J. (Ed.) Community, culture, difference. London: Lawrence \& Wishart, 1990.

SCOTT, J.C. Weapons of the weak: everyday forms of peasant resistance. Massachusetts: Yale University, 1985.

SCOTT, J.C. 'Everyday forms of peasant resistance'. The Journal of Peasant Studies, Vol. 13, No. 2, January 1986, p. 5-35.

SIGAUD, L. Os clandestinos e os direitos. Estudo sobre trabalhadores da cana-de-açúcar de Pernambuco. São Paulo: Livraria Duas Cidades, 1979.

. Greve nos engenhos. Rio de Janeiro: Paz e Terra, 1980.

. 'Trabalho assalariado e trabalho familiar no Nordeste'. Anuário Antropológico, No.79, 1981, p. 181-99.

SILVA, M.A.M. 'Destinos e trajetórias de camponeses migrantes'. Anais VIII Encontro Nacional de Estudos Populacionais, Vol. 3, ABEP, 1992, p. 161-77.

TEMPLE, B. Polish identity and community. Occasional Paper Number 38. Manchester: University of Manchester, 1994.

THOMPSON, E.P. The making of the English working class. London. Victor Gollancz Ltd, 1965. - A formação da classe operária inglesa. Volume I: A árvore da liberdade. RJ: Paz e Terra, 1987. 
VAN ONSELEN, C. 'Worker consciousness in black miners: Southern Rhodesia, 1900-1920'. Journal of African History, Vol. XIV, No.2, 1973, p. 237-55.

'The reconstruction of a rural life from oral testimony: critical notes on the methodology employed in the Study of a Black South African Sharecropper'. The Journal of Peasant Studies, Vol. 20, No. 3, April 1993, p. 494-514.

RELATÓRIOS DO ASSISTENTE DE PESQUISA (RAP): RAP. 1.12.95, 12 ps. RAP. 8.12.95, 5 ps.

RELATÓRIOS DO SERVIÇO PASTORAL DE MIGRANTES (RSPM) October, November and December 1994, 3 p.

(Recebido para publicação em dezembro de 1998) 